\title{
The link between urbanization and air pollution in Turkey: Evidence from dynamic Autoregressive Distributed Lag simulations
}

Alper Aslan ( $\square$ alperaslan@erciyes.edu.tr)

Erciyes Universitesi https://orcid.org/0000-0003-1408-0921

BUKET ALTINOZ

Nisantasi University: Nisantasi Universitesi

BAKI OZSOLAK

Nevsehir Haci Bektas Veli Universitesi

Research Article

Keywords: Urbanization, Air Pollution, Turkey, DARDL

Posted Date: February 25th, 2021

DOI: https://doi.org/10.21203/rs.3.rs-222964/v1

License: (c) (i) This work is licensed under a Creative Commons Attribution 4.0 International License. Read Full License 


\section{Abstract}

This study investigates the relationship between urbanization and air pollution in Turkey. Dynamic ARDL method was used for the period 19602014. According to the findings, there is a positive and statistically significant relationship between long-term urbanization and Co2. If urbanization increased by $1 \%$, carbon emissions increased by $0.02 \%$. There is a similar relationship between the shocks that will occur in population growth and $\mathrm{Co} 2 \mathrm{emission}$ in the long term. However, there is a negative and statistically insignificant relationship between the two variables. In the relationship between GDP and Co2, there is a positive relationship in the long term. GDP increase of $1 \%$ increases Co2 emissions by $0.11 \%$. There is a similar relationship between long-term GDP shocks and $\mathrm{Co} 2$ emissions. According to short-term analysis results, energy consumption increases $\mathrm{Co} 2$ emissions by the same rate as GDP. However, the astonishing result of the study emerges here. Empirical results show that a long-term positive shock in energy consumption reduces $\mathrm{CO} 2$ emissions and a negative shock increases pollution. According to these results, Turkey has not reached the point of sustainable growth. For this reason, this developing country needs to make regulatory implementations and determine future policies for these impacts affecting air pollution.

\section{Introduction}

A 2018 report by the World Health Organization (WHO, 2018) has shared stunning statistics on air pollution. According to this, 9 out of 10 people in the world, or $90 \%$ of the world's population, breathe contaminated air. 7 million people die every year in the world due to air pollution. The same report once again highlighted that air pollution is one of the most serious problems facing the world and one of the most threatening factors in human life.

Air pollution occurred at the end of a long process. Air pollution has increased as a result of increased human needs in developing economies. The increasing population brings with urbanization, energy demand and large infrastructure constructions (Rafiq et al., 2016). The United Nations Population Fund (UNFPA, 2019) report states that the total population of world reached 7.8 billion in 2019. From this point of view, it is seen that population growth is an important factor in air pollution. More than $50 \%$ of the world population lives in cities. The right of people to move freely to a different place causes increase of migration. Waves of migration from rural areas are often due to job opportunities in cities. Better health care in cities and higher wage sourcing are other important causes of migration. It is known that the number of vehicles has increased with the increase of urbanization. This causes emissions that cause air pollution. On the other hand, with increasing urbanization, the possibilities of infrastructure services are restricted and other damages such as water pollution and soil pollution are occurring. Increasing the need for fossil fuels, energy sources, soil, food and water is the main harms of urbanization (Ali et al., 2019).

Studies on energy demand and other harms of urbanization have been carried out. For example, Wang et al. (2016) in ASEAN countries, Wang et al. (2016b) in BRICS countries, Shahbaz et al. (2014) in the UAE, Dogan and Turkekul (2016) in USA, Al-Mulali et al. (2013) in MENA countries; they have identified the negative relationship between urbanization, energy consumption and air pollution. Studies in the literature are usually based on a single-country time series or cross-country panel data studies. Very little work has been done for Turkey on urbanization and its effects. Topcu et al. (2016) is the only study that directly examines the relationship between urbanization and carbon emissions for Turkey by using VECM method. The study covers the period 1960-2011. They determined that the causality relationship is from urbanization to Co 2 emissions.

For Turkey, one of the most important tourism centers of recent years, the fact that the issue of air pollution is not associated with urbanization is a major deficiency in the literature. Filling this gap will be the big contribution of our study to the literature. The majority of the work was carried out for China. As stated in the literature, the models usually cover analysis of STIRPAT, panel data or single-country time series. Methods such as ARDL or VECM are often used in single-country analysis. For this reason, dynamic ARDL method was used in our study. We are aware that we will be pioneers in this regard, which is another gap in the literature. In terms of method and example examined, the aim of doing a study to fill the gap in two ways constitutes our motivation. In the first part of the study is introduction, second the literature review, the third part contains methodology and data, empirical results in fourth part and the final chapter contains conclusion.

\section{Literature Review}

$\mathrm{Co} 2$ is generally used as a measure of air pollution in the literature. The relationship between urbanization and air pollution generally turns into urbanization and Co2. Energy use and GDP are an indispensable variable in examining this relationship. The relationship between energy consumption and GDP is in the literature, so in accordance with the purpose of our study, studies involving urbanization and the Co2 relationship have been studied mainly. Kavi Kumar and Viswanathan (2013) have studied two groups in India: urban and rural residents. The impact of carbonintensive energy consumption on environmental pollution has been examined for the period 2009-2010. In their work, they reached an inverse-u curve between income and pollution in the areas where the city is located. However, Li et al. (2018) in their study for China, they found a u-shaped format between urbanization and Co2 emissions. Cirilli and Veneri (2014) examined the relationship between transport and urbanization in the case of Italy. They concluded that transportation was one of the major causes of Co2 emissions in large settlements. They also stated that demographic characteristics are an important factor in Co2 emissions per capita. In another study, urbanization and Co2 emissions are examined according to geographical features. Wang Y. et al. (2019) in their study, China was divided into three groups: the central, eastern and western regions. According to the results of regression analysis, they stated that the eastern region of the country with the lowest positive effect on Co2 
emissions was. Wang et al. (2019) used dynamic unrelated seemly regression (DSUR) method for the period of 1990-2014. The countries analyzed are APEC. Panel data study stated that urbanization, industrial development and economic development cause air pollution through Co2.

Chikaraishi et al. (2015) they used the STIRPAT model in their work. In the study using panel data method, 140 countries were examined. $1980-2008$ was selected as the observation period. They stated that urbanization would reduce air pollution if high income and service sectors share in the economy increased. Bai et al. (2019) in their study for China, they performed regression and analysis with the STIRPAT model. They found that urbanization had a positive impact on air pollution even at the point where the population rate reached $75 \%$ in cities. Zhang et al. (2018) in their studies, they analyzed population urbanization and land urbanization in two groups. They chose the period $2005-2014$ as the observation range and examined China. Panel data study was applied with the STIRPAT model. According to the findings, the effect of population urbanization on Co2 was insignificant and land urbanization had significant and positive effect. Zhang et al. (2017) they conducted panel data studies involving 141 countries. They reached an inverse-u curve between Co2 and urbanization. They stated that the turning point was $73,80 \%$.

Zhang et al. (2020) they examined China with a decomposition analysis. The authors have investigated how China can achieve its 2030 Co 2 target. They have used urbanization, GDP and energy consumption variables in their work. The structural properties of energy consumption are associated with urbanization and other variables. They argued that urbanization can be achieved through the increase in GDP, technological progress and cultural development, and have argued that non-fossil fuel consumption will increase with the increase in urbanization. Not only did urbanization reduce Co2 demand, but they also needed a strong economic structure. Another study is Dong et al. (2019) they investigated the effect of urbanization and industrialization on $\mathrm{Co} 2$ emissions in developed countries with regression analysis. Urbanization, GDP, industrial development, GDP per capita and energy consumption have been used as variables. In the study, urbanization was grouped as low level and intermediate level. According to the results obtained, an important relationship between $\mathrm{Co} 2$ and urbanization could not be determined in the low-level urbanization group. However, in the mid-level urbanization group, a negative relationship between Co2 and urbanization was determined. They stated that the income level is critical in determining these threshold values. Lin et al. (2017) conducted a panel data study with 53 countries. In the study using the STIRPAT model, 1991-2013 period was investigated. Co2 emissions were analyzed by dividing them into 9 sub-factors. The Countries were analyzed in two groups as middle-upper income countries and middle-low income countries. They found that urbanization and revenue growth in the middle-low countries group would not increase $\mathrm{Co} 2$ emissions. However, in the middle-upper income group, urbanization had a low impact on Co2 emissions. Liu and Liu (2019) have found similar results for China. Accordingly, urbanization has a negative effect on Co2 emissions in the early stages, whereas in cases where urbanization is progressing, the negative effect turns positive and disappears over time.

Liu and Bae (2018) analyzed the relationship between Co2 emissions, urbanization and energy density with ARDL and VECM analysis in the case of China. According to the results of long-term analysis, Co2 emissions increase by $1 \%$ if urbanization increases by $1 \%$. Co 2 emissions increase by $1.1 \%$ if energy density increases by $1 \%$. In long-term causality analysis, they determined that there was no relationship between urbanization and Co2, but that energy density had a relation between Co2 emissions and causality. Zhang and Lin (2012) stated that urbanization in China increases energy consumption and Co2 emissions. Liu (2009) in their study using ARDL and causality methods in the long-term causal relationship between urbanization, energy use, GDP for China, Krey et al. (2012) determined the same causal relationship for both China and India using an integrated assessment model. In the panel data study of 99 countries using the STIRPAT model, Poumanyvong and Kaneko (2010) stated that urbanization had a positive effect on carbon emissions and energy consumption.

York et al. (2003) using the STIRPAT model, they analyzed GDP, population, carbon emissions and energy consumption. The country groups are divided into tropical and non-tropical countries. GDP increase in the study conducted by OLS method also increases energy consumption and carbon emissions. On the other hand, according to the findings, the population has an equal effect on both direct energy consumption and CO2 emissions. They stated that Co 2 emissions increased by $0.624 \%$ if urbanization increased by $1 \%$. Variable urbanization, which mainly affects carbon emissions and energy consumption, has been identified. Shahbaz et al. (2015) analyzed the direct energy consumption and urbanization relationship for Malaysia. As a variable, GDP, trade clearance and capital stock variables were also used. They used STIRPAT and ARDL methods in their studies covering the period of 1971-2011. According to the findings, urbanization is the main reason affecting energy consumption. On the other hand, the direction of causality is from urbanization to energy consumption. Causality relationship between GDP and energy consumption has also been determined. Causality is from growth to energy consumption. Another similar study was conducted by Sharma (2011) with dynamic panel data analysis of 69 countries. In this study, factors affecting CO2 emissions were investigated for 1985-2005 period. In the study, countries were divided into three, high, medium and low income. Urbanization in all three groups negatively affects Co2 emissions. GDP and energy consumption have a positive effect on $\mathrm{Co} 2$ emissions. Urbanization has a negative impact on $\mathrm{Co} 2$ emissions as a result of aggregate analysis of all countries, while GDP and primary energy consumption alone have a positive impact on $\mathrm{Co} 2$ emissions. Another study examining urbanization and Co2 emissions, divided by income levels of country groups, was conducted by Martínez-Zarzoso (2008). 1975-2005 was selected as the period interval and FGLS method was selected as the analysis method. Urbanization and Co2 emissions flexibility in the high-income group were determined to be negative, while the flexibility coefficient in low income group countries was bigger than unity (2.8\%). While GDP has a positive effect on carbon emissions in all groups, energy efficiency has a negative effect.

\section{Data, Model Specification And Testing Procedure}

\subsection{Describes of variables, and model specification}

Page $3 / 12$ 
This paper focused on Turkey uses annually time series data for the period from 1960 to2014. Time period selection is based on the data availability. $\mathrm{CO}_{2}$ emission (kt) is used as the dependent variable. The main independent variable is urban population growth (annual \%) and it is proxy for urbanization. Other explanatory variables are energy use ( $\mathrm{kg}$ of oil equivalent per capita) and GDP (constant 2010 US\$), respectively. All variables obtained from World Development Indicators database offered by the World Bank, and these are expressed in logarithms.

The aim of this paper is to explain the effects of urbanization (EC) to carbon dioxide emissions $\left(\mathrm{CO}_{2}\right)$. First, a basic production function accounting framework yields:

$\mathrm{CO}_{2}=f(U R B, E U, G D P)(1)$

where $\mathrm{CO}_{2}$ denotes carbon dioxide emissions, URB is urban population growth, $E C$ is energy consumption, and GDP displays gross domestic product (constant 2010 US\$).

The study's empirical model is borrowed from recent literature (Sharma, 2011; Ali et al., 2017; Ali et al., 2019), as follows:

$$
\log { }_{-} c o 2_{t}=\beta_{0}+\beta_{1} \log \_u r b_{t}+\beta_{2} \log \_e u_{t}+\beta_{3} \log \_g d p_{t}+\mu_{t}
$$

where $\beta s$ are coefficients of dependent variables, $\mu$ is error correction terms, $t$ denotes time series.

\subsection{Methodology}

In this study, it is used the dynamic ARDL model based on dynamic simulations as seen in Khan et al. (2019), Sarkodie et al. (2019), and Danish and Ulucak (2019). Main equation can be written as (Jordan and Phillips, 2018):

$$
\begin{aligned}
\Delta(y)_{t}= & \alpha_{0}+\theta_{0}(y)_{t-1}+\theta_{1}\left(x_{1}\right)_{t-1}+\cdots+\theta_{k}\left(x_{k}\right)_{t-1}+\sum_{i=1}^{p} \alpha_{i} \Delta(y)_{t-1}+ \\
& \sum_{j=0}^{q_{1}} \beta_{1 j} \Delta\left(x_{1}\right)_{t-j}+\cdots+\sum_{j=0}^{q_{k}} \beta_{k j} \Delta\left(x_{k}\right)_{t-j}+\varepsilon_{t}
\end{aligned}
$$

where $y$ denotes change in the dependent variable, $\alpha_{0}$ is intercept, and $t-1$ displays independent variables' maximum level of $p$ and with lags $q_{k}$ in the first differences operator with the error term $(\varepsilon)$ in time $t$. The existence of the cointegration relationship is demonstrated by $\mathrm{F}$-statistic value. With this value, the null hypothesis is tested, indicating that all parameters on the repressors appearing in levels, plus the coefficient on the lagged dependent variable are jointly equal to zero $\left(H_{0}=\theta_{0}+\theta_{1}+\cdots+\theta_{k}=0\right)$.

The starting point of Jordan and Phillips (2018) is to eliminate the problems in the investigation of short and long run relationships between variables that arise in the ARDL model. The dynamic ARDL method can estimate, stimulate, and plot to predict automatically spurious changes in the dependent variable that are due to a regressor while other factors constant (Danish and Ulucak, 2019). In order to apply the method, the series must be stationary in the first order. This method is used up to 5000 simulations of the vector of parameters (Sarkodie et al., 2019).

Based on empirical specification expressed in Eq. (3), the error correction form of ARDL bounds procedure is demonstrated as

$$
\begin{gathered}
\Delta \log { }_{-} c o 2_{t}=\alpha_{0} \log { }_{-} c o 2_{t-1}+\beta_{1} \Delta \log _{-} u r b_{t}+\theta_{1} \Delta \log { }_{-} u r b_{t-1}+\beta_{2} \Delta \log { }_{-} e u_{t}+ \\
\theta_{2} \Delta \log { }_{-} e u_{t-1}+\beta_{3} \Delta \log { }_{-} g d p_{t}+\theta_{3} \Delta \log { }_{-} g d p_{t-1}
\end{gathered}
$$

\section{Empirical Findings}

In the first step, series must be proved to be stationary at the first order. Essentially, Jordan and Phillips (2018) suggested that the condition I(1) is a necessity for the dependent variable, and that at least, the other series should not integrated higher than stationary at I(1). For this purpose, PhillipsPerron and DF-GLS unit root tests performed such as Jordan and Phillips (2018). Both test results are presented in Table 1. The test results suggested that the null hypothesis expressing the presence of unit root is rejected in all series, so all variables are integrated of first order. 
Table 1

Unit root test results

\begin{tabular}{|c|c|c|c|c|}
\hline & Phillips-Perr & & DF-GLS & \\
\hline Variables & Intercept & Trend and Intercept & Intercept & Trend and Intercept \\
\hline $\log \_\mathrm{co} 2$ & $-5.186742^{*}$ & -2.719103 & 0.970230 & -1.030427 \\
\hline log_eu & -1.286820 & -2.470342 & $1.677085^{\star \star \star}$ & -2.192721 \\
\hline $\log _{\text {ggdp }}$ & -0.416314 & -2.734658 & $3.334205^{*}$ & -2.449215 \\
\hline log_urb & -1.340795 & -2.175963 & -1.293408 & -2.570320 \\
\hline$\Delta \log \_c 02$ & $-6.944481^{*}$ & $-8.141968^{*}$ & $-6.720731^{*}$ & $-7.443251^{*}$ \\
\hline$\Delta \log _{-}$eu & $-7.157204^{*}$ & $-7.280449^{\star}$ & $-6.146791^{*}$ & $-6.811597^{\star}$ \\
\hline$\Delta \log _{-} g d p$ & $-7.173449^{*}$ & $-7.123746^{*}$ & $-6.248163^{*}$ & $-6.853735^{\star}$ \\
\hline$\Delta \log _{-} u r b$ & $-4.902297^{*}$ & $-4.855985^{*}$ & $-4.847840^{*}$ & -4.913052 \\
\hline
\end{tabular}

After providing the most important condition required by dynamic ARDL, the existence of cointegration relationship between series is tested. However, it is investigated whether the model has any econometric problem and autocorrelation problem is determined. Jordan and Phillips (2018) proposed the elimination of the problem in such a situation and the re-estimation of the results. Accordingly, all results obtained are presented in two groups as before and after overcoming the problem. Firstly, the results of ARDL cointegration showed that F-statistic value in the case of autocorrelation is significant at $1 \%$ statistically significance level, whereas both F-statistic and t-statistic values are above the critical values after the problem is resolved. Hence, the null hypothesis of no cointegration is rejected. The cointegration results are based on response surface regression with the accurate critical values and p-values approximation proposed by Kripfganz and Schneider (2018). 
Table 2

Dynamic ARDL results (dependent variable: $\Delta$ log_co2)

\begin{tabular}{|c|c|c|c|c|c|c|}
\hline \multicolumn{7}{|l|}{ ARDL Bound Test Results } \\
\hline & \multicolumn{2}{|l|}{$10 \%$} & \multicolumn{2}{|l|}{$5 \%$} & \multicolumn{2}{|l|}{$1 \%$} \\
\hline & $\mathrm{I}(0)$ & $\mathrm{I}(1)$ & $\mathrm{I}(0)$ & $\mathrm{I}(1)$ & $\mathrm{I}(0)$ & $\mathrm{I}(1)$ \\
\hline F-stat $1: 7.390^{*}$ & 3.280 & 4.273 & 3.987 & 5.090 & 5.707 & 6.977 \\
\hline t-stat $_{1}:-2.270$ & -2.570 & -3.210 & -2.860 & -3.530 & -3.430 & -4.100 \\
\hline F-stat $2: 25.620^{\star}$ & 3.280 & 4.273 & 3.987 & 5.090 & 5.707 & 6.977 \\
\hline t-stat $_{2}:-3.270^{\star \star \star}$ & -2.570 & -3.210 & -2.860 & -3.530 & -3.430 & -4.100 \\
\hline \multicolumn{7}{|l|}{ Dynamic Stimulated ARDL Results } \\
\hline Variables & \multicolumn{3}{|c|}{ Coefficient [Standard Error] } & \multicolumn{3}{|c|}{ Coefficient [Standard Error] } \\
\hline $\log _{-} \operatorname{co} 2_{t-1}$ & \multicolumn{3}{|c|}{$-0.12239581^{\star \star}[0.028]$} & \multicolumn{3}{|c|}{$-0.100402^{\star}[0.002]$} \\
\hline$\Delta \log _{-} u r b_{t}$ & \multicolumn{3}{|c|}{$0.024157[0.551]$} & \multicolumn{3}{|c|}{$-0.0032757[0.893]$} \\
\hline $\log _{-} u r b_{t-1}$ & \multicolumn{3}{|c|}{$0.0331903[0.106]$} & \multicolumn{3}{|c|}{$0.0259736^{\star \star}[0.020]$} \\
\hline$\Delta \log _{-} \mathrm{eu}_{\mathrm{t}}$ & \multicolumn{3}{|c|}{$1.075278^{*}[0.000]$} & \multicolumn{3}{|c|}{$1.005037^{\star}[0.000]$} \\
\hline log_eut-1 & \multicolumn{3}{|c|}{$0.0291464[0.854]$} & \multicolumn{3}{|c|}{$-0.0182404[0.831]$} \\
\hline$\Delta \log _{-} g d p_{t}$ & \multicolumn{3}{|c|}{$0.0199898[0.885]$} & \multicolumn{3}{|c|}{$0.0302434[0.766]$} \\
\hline $\log _{-} g d p_{t-1}$ & \multicolumn{3}{|c|}{$0.1224413^{*}[0.049]$} & \multicolumn{3}{|c|}{$0.1188316^{*}[0.001]$} \\
\hline constant & \multicolumn{3}{|c|}{$-0.8824082^{\star \star}[0.039]$} & \multicolumn{3}{|c|}{$-0.8083431^{\star}[0.001]$} \\
\hline Obs. & \multicolumn{3}{|l|}{54} & \multicolumn{3}{|l|}{53} \\
\hline $\mathrm{R}^{2}$ & \multicolumn{3}{|l|}{0.7985} & \multicolumn{3}{|l|}{0.9091} \\
\hline sims & \multicolumn{3}{|l|}{5000} & \multicolumn{3}{|l|}{5000} \\
\hline Prob $>$ F & \multicolumn{3}{|c|}{$0.0000^{*}$} & \multicolumn{3}{|c|}{$0.0000^{*}$} \\
\hline Diagnostic tests & \multicolumn{6}{|c|}{ Chi-square[Prob.] } \\
\hline Breusch-Godfrey Serial Correlation LM Test & \multicolumn{6}{|c|}{$18.929^{a}[0.000]$} \\
\hline Heteroskedasticity Test: Breusch-Pagan-Godfrey & \multicolumn{6}{|c|}{$1.31[0.2516]$} \\
\hline
\end{tabular}

Table 2 also contains dynamic stimulated ARDL coefficient estimation results. Jordan and Phillips (2018) proposed this method to eliminate the complexity of short and long run coefficient estimation in the other ARDL method. In the case of autocorrelation problem, carbon dioxide emissions increase due to increases in energy consumption and GDP. However, the coefficient of urbanization, which we identified as the main explanatory variable, is positive in both short and long run, but it is statistically insignificant. The econometric problem faced undermines the reliability of these results. Therefore we adopted the coefficient estimation results in second column.

The coefficient of urbanization is found positive and statistically significant in long run, while this coefficient negative but statistically insignificant in the short run. We find that one percent increase in urbanization enhances 0.02 percent carbon dioxide emissions (as seen in Alam et al., 2017; Poumanyvong and Kaneko, 2010; Bekhet and Othman, 2017; Liddle, 2014; Pata, 2018; Ali et al., 2019). This means that environmental degradation rises with the increase in the urban population growth in Turkish provinces in the long run. This relationship can be attributed to the increase in the weight of industry and service sector in the economy and the relative decrease of the agricultural population. In addition, rapid production and consumption with urbanization lead to pollution. Another factor that increases carbon emissions in the long run is GDP growth. According to the coefficient estimation results, one percent increase in GDP increases carbon dioxide emissions almost 0.11 percent. Thus it can be say that Turkey seems not yet reached the stage of sustainable development. This result is critical for the future of the country. Although the shift on production from agriculture to industrial and service sector along with urbanization and increasing production in parallel with this support the GDP increase, 
environment-friendly policies in production processes should not be ignored. When the short run results are examined, it is observed that an increase in energy consumption increases the pollution at almost the same rate. This result is another indication that environmentally friendly energy sources are not used. All results considered together, the existence of a case against Turkey's environmental performance is draws attention.

Figure 1-3 plot the positive and negative shocks on urbanization, GDP and energy consumption in carbon dioxide emissions. Figure 1 illustrates how future positive and negative shocks in urbanization will have an impact on carbon dioxide emissions. Accordingly, a positive shock in urban population growth increases emissions, while a negative shock decrease. Although a positive and negative shock likely to emerge in the future in GDP has the same impact on pollution as urbanization, there is a completely different result in energy consumption. That is, as can be seen from Fig. 2, a future positive shock in the energy consumption reduces the pollution, while the negative shock increases the emissions. This unexpected impulse-response relationship signals that the country's future energy consumption composition will be more environmentally friendly.

\section{Conclusion And Policy Implications}

The aim of this study is to analyze urbanization and Co2 emissions relationship in the case of Turkey. The relationship between variables energy consumption, GDP and urbanization was analyzed by dynamic ARDL method. Short and long-term results were obtained in this study covering the period 1960-2014. An important and positive long-term relationship has been established between urbanization and Co2 emissions. Co2 emissions increased by $0.02 \%$ if urbanization increased by $1 \%$. This shows that the increase in urbanization in Turkey in the long term has increased carbon emissions. However, when looking at the results of short-term analysis, the relationship between the two variables is negative but statistically meaningless. For Turkey, this positive relationship between urbanization and carbon emissions brings with policy proposals for the future.

Another relationship between GDP and $\mathrm{Co} 2$, has achieved similar results. A similar directional relationship between the two variables has been determined. If GDP increases by $1 \%$, carbon emissions increase by $0.11 \%$. These results show that sustainable growth has not been achieved for Turkey. Because GDP increase provides positive effects such as technological innovation, efficiency in energy consumption, efficiency in the consumption of natural resources. On the other hand, with GDP growth, migration movements can take place from the countryside to the cities. In this case, which is an indicator of the transition from agricultural production to industrial production, Turkey should use its energy resources more effectively and reduce fossil fuel consumption. When looking at the relationship between energy consumption and carbon emissions for the short term, it has been observed that energy consumption directly increases emissions. This is an expected result for a developing country. However, unexpected results were observed in long-term analysis. According to these results, positive shocks in energy consumption reduce pollution. Negative shocks increase carbon emissions.

Consequently, urbanization policies are important in a developing economy like Turkey. The increase in industrial production, increase in energy demand and infrastructure problems caused by the inert use of resources resulting in increased urbanization. The increase in transportation vehicles used in cities increases the use of fossil fuels. This increases carbon emissions. Using vehicles that minimize emissions can be an important step to prevent the damage of urbanization. On the other hand, until recently, Turkey did not use fuels such as natural gas that caused less pollution in all its cities. Fossil fuels such as coal and fuel-oil are used extensively for heating purposes in rural areas and even in some areas in Turkey. With the increase of urbanization, the narrowing of job opportunities causes people to prefer cheaper heating methods. Another reason is that the necessary infrastructure has not been provided in some regions. As much as possible, the use of fuels that cause less emissions in the production sector and other areas, especially heating, is very important in reducing pollution. Renewable energy investments in Turkey need to be increased and used quickly. The fact that GDP growth is one of the factors that increase pollution in Turkey may be due to increased welfare levels of individuals. Increased welfare indicators, such as individuals who want to live in larger apartments and want to use personal vehicles instead of public transport, increase pollution. These two reasons alone lead to the use of more resources such as heating, electricity, oil, soil and water. Turkey needs to make arrangements for changes in consumption habits resulting from increased income. For example, to provide thermal insulation in new and old buildings in the country and to set a certain level of carbon emission limits on vehicles. However, the most important thing to do is to ensure efficiency in energy consumption, to create renewable energy sources and to minimize fossil fuel consumption.

\section{Declarations}

\section{Funding}

The author(s) received no financial support for the research, authorship, and/or publication of

this article.

\section{Contributions}

Writing-original draft, conceptualization: AA; writing-original draft: BA; data curation:

BO; supervision, project administration: $A$ A.

\section{Corresponding author}




\section{Ethics declarations}

\section{Ethics approval and consent to participate}

Not applicable

\section{Consent for publication}

Not applicable.

\section{Competing interests}

The authors declare that they have no competing interests.

\section{Additional information}

\section{Availability of data and materials section}

\section{References}

1. Ali R, Bakhsh K, Yasin MA (2019) Impact of urbanization on CO2 emissions in emerging economy: Evidence from Pakistan. Sustainable Cities Society 48:101553

2. Al-Mulali U, Fereidouni HG, Lee JYM, Sab CNBC (2013) Exploring the relationship between urbanization, energy consumption, and CO2 emission in MENA countries. Renew Sustain Energy Rev 23:107-112

3. Bai Y, Deng X, Gibson J, Zhao Z, Xu H (2019) How does urbanization affect residential CO2 emissions? An analysis on urban agglomerations of China. J Clean Prod 209:876-885

4. Chikaraishi M, Fujiwara A, Kaneko S, Poumanyvong P, Komatsu S, Kalugin A (2015) The moderating effects of urbanization on carbon dioxide emissions: A latent class modeling approach. Technological Forecasting Social Change 90:302-317

5. Cirilli A, Veneri P (2014) Spatial Structure and Carbon Dioxide (CO2) Emissions Due to Commuting: An Analysis of Italian Urban Areas. Reg Stud 48(12):1993-2005

6. Dogan E, Turkekul B (2016) CO2 emissions, real output, energy consumption, trade, urbanization and financial development: testing the EKC hypothesis for the USA. Environ Sci Pollut Res 23(2):1203-1213

7. Dong F, Wang Y, Water B, Hua Y, Zhang Y (2019) The process of peak CO2 emissions in developed economies: A perspective of industrialization and urbanization. Resources Conservation \&Recycling 141:61-75

8. Kavi Kumar K, S. and Viswanathan B (2013) Household level pollution in India: patterns and projections. Climate Dev 5(4):288-304

9. Krey V, O'Neill BC, van Ruijven B et al (2012) Urban and rural energy use and carbon dioxide emissions in Asia. Energy Econ 34:272-283

10. Li F, Liu C (2019) Regional disparity, spatial spillover effects of urbanisation and carbon emissions in China. J Clean Prod 241:118226

11. Li J, Huang X, Kwan M, Yang H, Chuai X (2018) The effect of urbanization on carbon dioxide emissions efficiency in the Yangtze River Delta, China. J Clean Prod 188:38-48

12. Lin S, Wang S, Marinova D, Zhao D, Hong J (2017) Impacts of urbanization and real economic development on CO2 emissions in non-high income countries: Empirical research based on the extended STIRPAT model. J Clean Prod 166:952-966

13. Liu X, Bae J (2018) Urbanization and industrialization impact of CO2 emissions in China. J Clean Prod 172:178-186

14. Liu Y (2009) Exploring the Relationship between Urbanization and Energy Consumption in China using ARDL (autoregressive distributed lag) and FDM (factor decomposition model). Energy 34(11):1846-1854

15. Martínez-Zarzoso I (2008) The Impact of Urbanization on Co2 Emissions: Evidence from Developing Countries. FEEM Working Paper No. 50.2008. Available at SSRN: https://ssrn.com/abstract=1151928 or http://dx.doi.org/10.2139/ssrn.1151928

16. Poumanyvong P, Kaneko S (2010) Does urbanization lead to less energy use and lower CO2 emissions? A cross-country analysis. Ecol Econ 70(2):434-444

17. Rafiq S, Salim R, Nielsen I (2016) Urbanization, openness, emissions, and energy intensity: a study of increasingly urbanized emerging economies. Energy Economy 56:20-28

18. Shahbaz M, Sbia R, Hamdi H, Ozturk I (2014) Economic growth, electricity consumption, urbanization and environmental degradation relationship in United Arab Emirates. Ecol Ind 45:622-631

19. Shahbaz M, Sbia R, Nanthakumar L, Afza T (2015) The Effect of Urbanization, Affluence and Trade Openness on Energy Consumption: A Time Series Analysis in Malaysia. Renew Sustain Energy Rev 47:683-693 
20. Sharma SS (2011) Determinants of carbon dioxide emissions: Empirical evidence from 69 countries. Appl Energy 88:376-382

21. Topcu M, Yazici M, Eagle G (2016) An Investigation of Causality between Urbanization and Carbon Emissions in Turkey. https://www.researchgate.net/publication/330114188_An_Investigation_of_Causality_between_Urbanization_and_Carbon_Emissions_in_Turkey 30/12/2019

22. United Nations Population Fund (UNFPA, 2019) State of World population 2019 report. https://turkey.unfpa.org/sites/default/files/pubpdf/SWP19\%20-\%20EN\%20report-web-\%204\%20April_6.pdf 29/12/2019

23. Wang Y, Chen L, Kubato J (2016) The relationship between urbanization, energy use and carbon emissions: evidence from a panel of Association of Southeast Asian Nations (ASEAN) countries. J Clean Prod 112(2):1368-1374

24. Wang Y, Li L, Kubato J, Khan R, Zhu X, Lu G (2016b) Does urbanization lead to more carbon emission? Evidence from a panel of BRICS countries. Appl Energy 168:375-380

25. Wang Y, Li X, Kang Y, Chen W, Zhao M, Li W (2019) Analyzing the impact of urbanization quality on CO2 emissions: What can geographically weighted regression tell us? Renew Sustain Energy Rev 104:127-136

26. Wang Z, Rasool Y, Zhang B, Ahmed Z, Wang B (2019) Dynamic linkage among industrialisation, urbanisation, and CO2 emissions in APEC realms: evidence based on DSUR estimation. Structural Change and Economic Dynamics. doi: https://doi.org/10.1016/j.strueco.2019.12.001

27. World Health Organization (WHO, 2018) World Health release Organizations new global air pollution data. https://www.ccacoalition.org/en/news/world-health-organization-releases-new-global-air-pollution-data 29/12/2019

28. York R, Rosa EA, Dietz T (2003) STIRPAT, IPAT and ImPACT: analytic tools for unpacking the driving forces of environmental impacts. Ecol Econ 46:351-365

29. Zhang C, Lin Y (2012) Panel estimation for urbanization, energy consumption and CO2 emissions: a regional analysis in China. Energy Policy 49:488-498

30. Zhang G, Zhang N, Liao W (2018) How do population and land urbanization affect CO2 emissions under gravity center change? A spatial econometric analysis. J Clean Prod 202:510-523

31. Zhang N, Yu K, Chen Z (2017) How does urbanization affect carbon dioxide emissions? A cross-country panel data analysis. Energy Policy 107:678-687

32. Zhang X, Geng Y, Shao S, Wilson J, Song X, You W (2020) China's non-fossil energy development and its 2030 CO2 reduction targets: The role of urbanization. Appl Energy 261:114353

\section{Figures}



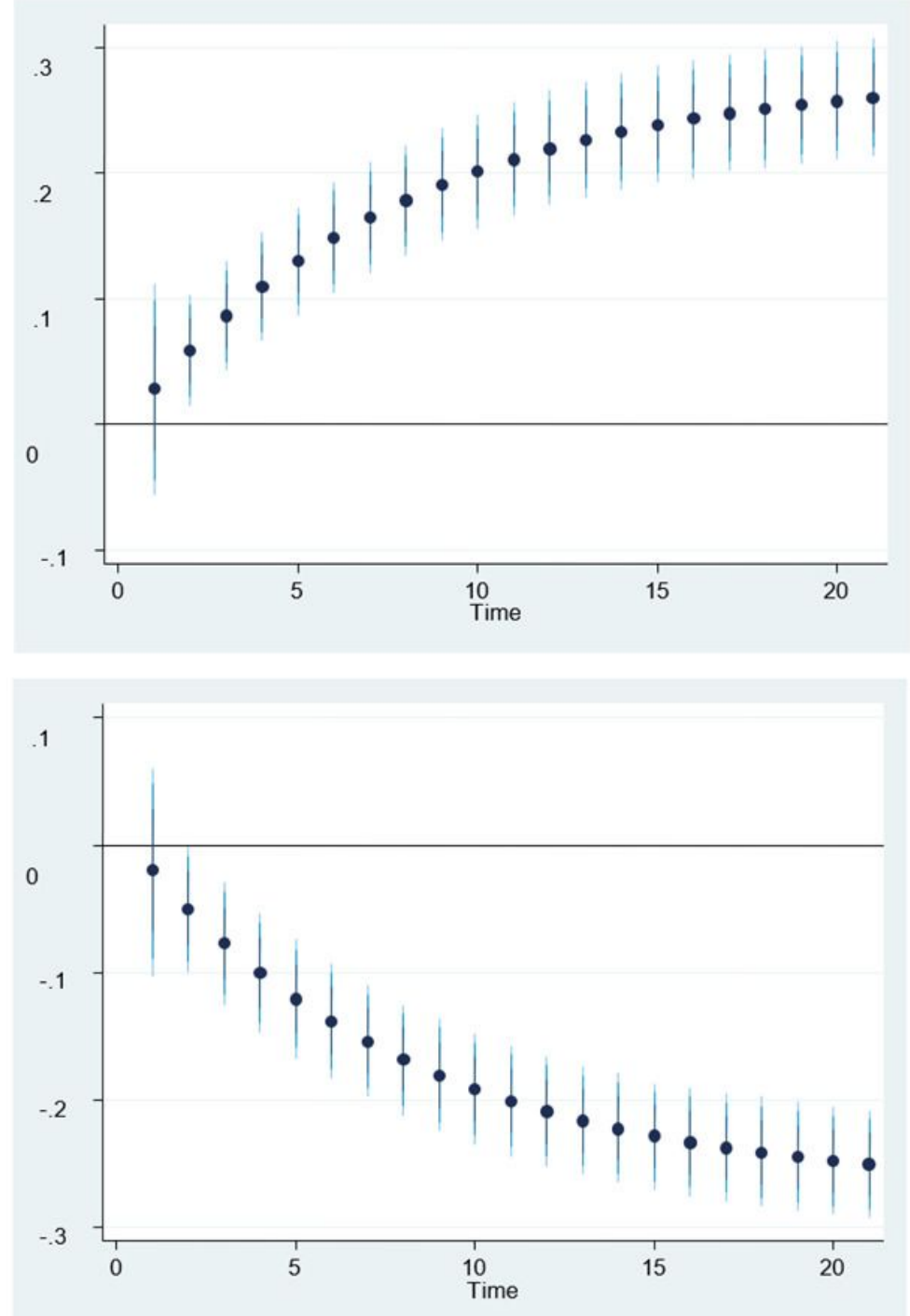

\section{Figure 1}

$(+/-1 \%)$ changes in predicted urbanization on $\mathrm{CO} 2$ emissions 

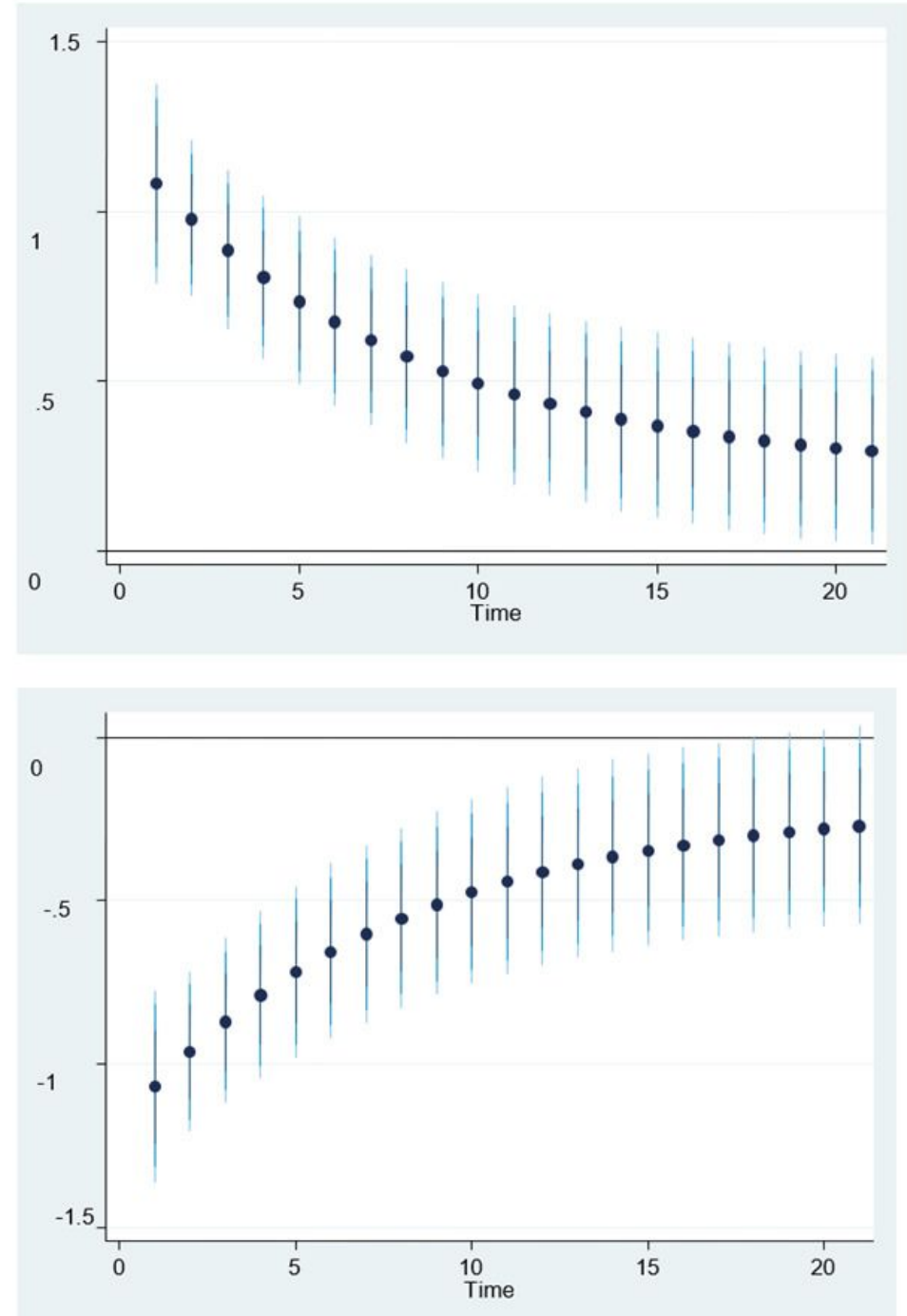

Figure 2

$(+/-1 \%)$ changes in predicted energy consumption on $\mathrm{CO} 2$ emissions 

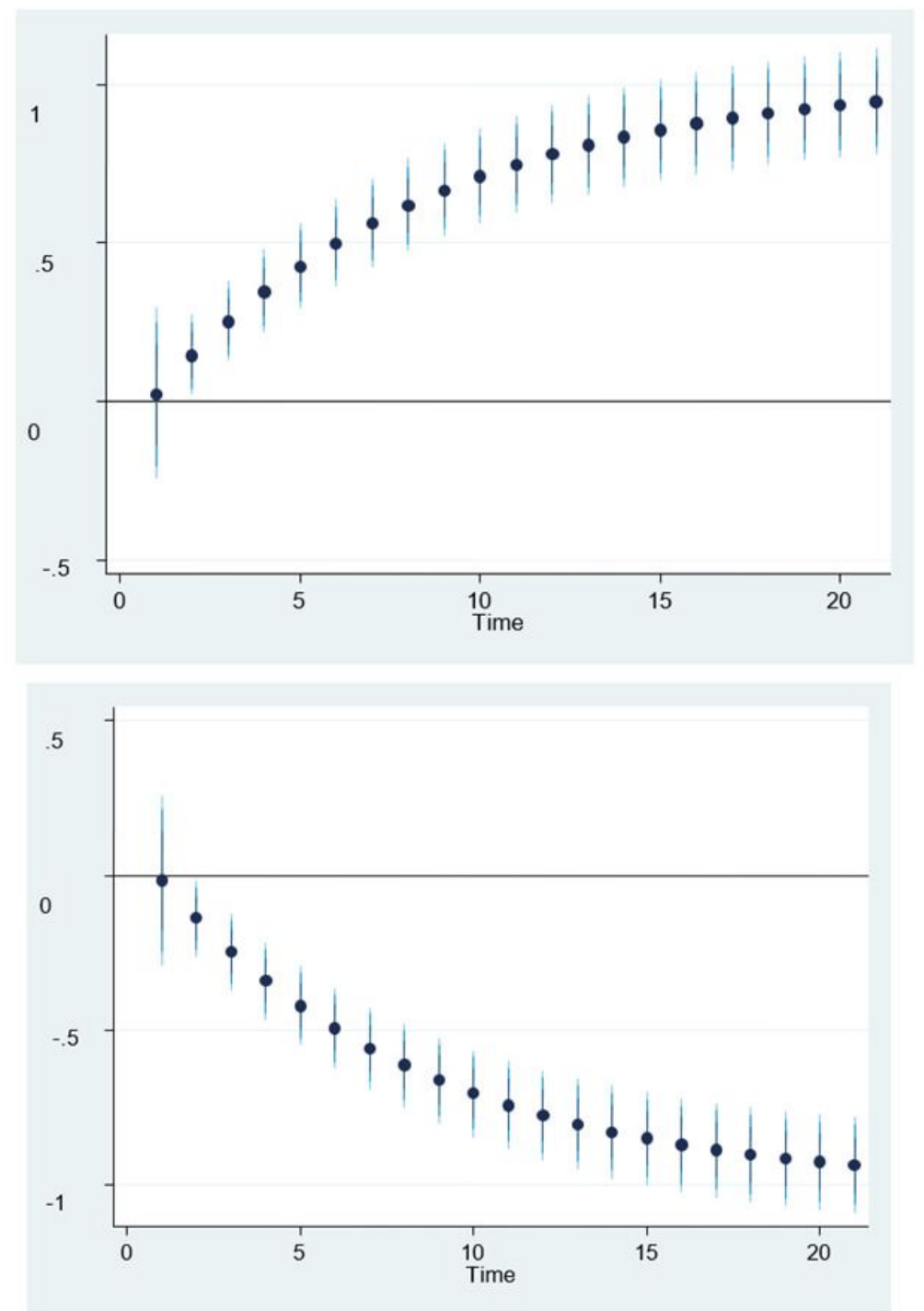

Figure 3

$(+/-1 \%)$ changes in predicted economic growth on $\mathrm{CO} 2$ emissions 